\title{
Will serum enzymes and other proteins find a clinical application in the early diagnosis of myocardial infarction?
}

\author{
Adam D Timmis
}

Until recently there was little interest in the early diagnosis of myocardial infarction because the duration of symptoms had little impact on the hospital management strategy. Attitudes changed after the publication of the major mortality studies of thrombolytic therapy which showed not only that treatment improves prognosis but also that the earlier it is given after the onset of symptoms the greater is the benefit. ${ }^{1-4}$ This stimulated a review of the three diagnostic methods used clinically for the diagnosis of acute myocardial infarction (electrocardiogram, enzyme analysis, non-invasive imaging) to determine which could provide the earliest diagnosis. ${ }^{5}$

There is no doubt that in terms of cost, practicality, and accuracy the presenting electrocardiogram remains the best method for early diagnosis. Regional ST elevation occurs within seconds of the onset of coronary occlusion ${ }^{67}$ and its diagnostic specificity for acute infarction is close to $100 \% .^{89}$ Nevertheless, its sensitivity may be as low as $60 \%$, reflecting the significant minority of patients who present with non-diagnostic changes such as left bundle branch block, ST depression, or $\mathrm{T}$ wave inversion: occasionally, the presenting electrocardiogram is entirely normal. ${ }^{89}$ In the past, serum enzyme analysis has proved useful for retrospective confirmation of infarction in these patients, but the timing of enzyme release and until recently the logistics of the method effectively ruled it out as a means of early diagnosis. Now, however, kits are available for the rapid analysis of creatine kinase and its $\mathrm{MB}$ isoenzyme and a myoglobin assay can be diagnostic within $4 \mathrm{~h}$ of the onset of symptoms. ${ }^{10-12}$ If these serum markers of myocardial infarction provide early diagnosis when the electrocardiogram is non-diagnostic will they save lives by allowing increased application of thrombolytic therapy and other interventions aimed at reducing mortality? ${ }^{12}$ Though serum markers of myocardial infarction may permit early diagnosis in cases where the electrocardiogram is unhelpful, this is unlikely to improve outcome. Indeed, there is real concern that it may have the opposite effect by leading to the use of thrombolytic agents in a group of patients in which the risk of treatment exceeds the potential benefit.

If serum markers of myocardial infarction are to be useful in early diagnosis it will be in patients who present with chest pain and left bundle branch block. In those in whom infarction is confirmed mortality is high and there is much to gain from successful thrombolysis. ${ }^{13}$ However, it is questionable whether this role will be realised because most cardiologists would not wish to wait for laboratory data before starting treatment of these high risk patients. Patients with chest pain and other non-diagnostic electrocardiogram patterns have a much better prognosis and do not require such early diagnosis and treatment. Thus Yusuf et al found that only $1 \cdot 2 \%$ of patients entered into the ISIS-1 (International Study of Infarct Survival) trial developed cardiac arrest or died when the presenting electrocardiogram was nondiagnostic compared with $11 \%$ when it showed ST elevation. ${ }^{9}$ Of course, these were selected, low risk patients not all of whom had a definite infarct. Nevertheless, the database of $>1000$ consecutive patients with acute infarction treated at Newham General Hospital confirms that patients without ST elevation have a hospital mortality of $<5 \%$, which is about one third that seen in patients with ST elevation. Clearly, therefore, hospital outcome in these patients with non-diagnostic electrocardiograms is good compared with patients with ST elevation, and this must diminish the potential value of thrombolytic therapy and other interventions designed to improve survival. Indeed, subgroup analysis of the ISIS-2 trial, indicated that mortality reduction in response to treatment was greatest in subgroups at greatest risk of death (for example, women, older patients, patients with previous infarction or anterior infarction), and no apparent benefit for either streptokinase or aspirin could be demonstrated in patients with normal electrocardiograms or ST depression. ${ }^{2}$ In this latter respect, the finding accorded with the GISSI subgroup analysis. ${ }^{1}$ Only the LATE study has suggested a small benefit in outcome for patients without ST elevation randomised to thrombolytic therapy, but it is not clear to what extent patients with left bundle branch block confounded the mortality statistic. ${ }^{14}$ The balance of evidence from subgroup analyses of the randomised trials of thrombolytic therapy, therefore, tends to strengthen the hypothesis that patients with non-diagnostic electrocardiograms may not show the same benefit from thrombolytic therapy as patients with ST elevation. If true, this calls into question the need for early diagnosis by rapid analysis of enzymes or other proteins 
released from necrosing cardiac myocytes.

Why do some patients with myocardial infarction present without ST elevation, why do these same patients have such a good prognosis, and why do they obtain little apparent benefit from thrombolytic therapy? A unifying hypothesis that may account for all these observations is provided by DeWood et al's finding of a $35 \%$ coronary patency rate in patients with "transmural" infarction after the first $12-24 \mathrm{~h}^{15}$; in non-Q wave infarction the patency rate is as high as $74 \% .{ }^{16}$ Even in the early hours after infarction, patency rates of $29 \%$ have been reported and in these patients ST elevation resolves very rapidly, the enzyme rise is reduced, and indices of left ventricular damage (ejection fraction, QRS score, $\mathbf{Q}$ wave development) are lower than in patients with coronary occlusions. ${ }^{17}$ ST changes also resolve rapidly after succ̀essul thrombolysis ${ }^{17-19}$ and the assumption must be that, in many patients with non-diagnostic electrocardiograms, there is spontaneous thrombolysis by endogenous mechanisms before presentation to hospital. This causes ST elevation to resolve and aborts the process of infarction. This limits infarct size and reduces hospital mortality. Of course, cardiac enzymes and other serum markers of myocardial injury are often raised on presentation (reflecting recent, not necessarily continuing, infarction) but if the coronary artery is already patent no additional benefit can be expected from thrombolytic therapy, which merely exposes the patient to the risk of haemorrhagic side effects. Treatment directed at preserving coronary patency with aspirin and heparin is the logical alternative. This presumably accounts for the value of these drugs in unstable angina, ${ }^{20}$ another chest pain syndrome caused by subocclusive coronary disease, ${ }^{21}$ which (as recently confirmed at the 1993 meeting of the European Society of Cardiology by the TIMI (Thrombolysis in Myocardial Infarction) investigators (TIMI 3B Trial) is not helped by thrombolytic therapy.

At present the use of laboratory tests to make an early diagnosis of myocardial infarction in the patient who presents with chest pain and a non-diagnostic electrocardiogram is not clinically justified. This policy would be expensive because even if sensitivity and specificity were $100 \%$ only about half the patients tested would have a positive result. ${ }^{9}$ In fact a recent study shows that the sensitivity of the tests early after the onset of symptoms is lower than that of the ECG, ranging from $34 \%$ for creatine kinase to $57 \%$ for myoglobin. So those patients who might benefit most from receiving early thrombolytic therapy would be those least likely to be identified.22 Most importantly, however, it must be recognised that in the absence of left bundle branch block patients with non-diagnostic electrocardiograms have a good prognosis and there is no clear evidence that it can be improved by thrombolytic therapy. Serial electrocardiograms are a cheaper and more practical alternative for diagnostic purposes: if ST elevation, left bundle branch block, or signs of true posterior infarction develop it will indicate coronary occlusion and the need for thrombolysis. Inevitably, this conservative policy will mean that occasionally patients with electrocardiographically-silent coronary occlusions will not receive the thrombolytic therapy that would have benefited them. However, much more worrying are the consequences of inappropriate thrombolytic therapy in patients who do not benefit-about five in every thousand-who experience a major bleed or fatal haemorrhagic stroke as a direct result of the treatment. ${ }^{2}$

Gruppo Italiano per lo Studio della Streptochinasi nell'Infarcto Miocardico (GISSI). Effectiveness of intravenous thrombolytic treatment in acute myocardia infarction. Lancet 1986;i:397-402.

2 ISIS-2 Collaborative Group. Randomised trial of intravenous streptokinase, oral aspirin, both, or neither among 17,187 cases of suspected acute myocardial infarction: ISIS-2. Lancet 1988;ii:349-60.

3 Wilcox RG, Von der Lippe G, Olsen CG, et al, for the ASSET Study Group. Trial of tissue plasminogen activator for mortality reduction in acute myocardial infarction. Anglo-Scandinavian Study of Early Thrombolysis Anglo-Scandinavian Study of

4 AIMS Trial Study Group. Effect of intravenous APSAC on mortality after acute myocardial infarction: preliminary mortality after acute myocardial infarction: preliminary report of a

5 Timmis AD. Early diagnosis of acute myocardial infarction. Br Med f 1990;301:941-2.

6 Griffin B, Timmis AD, Crick JCP, Sowton E. The evolution of myocardial ischaemia during percutaneous transtion of myocardial ischaemia during percutaneous trans-
luminal coronary angioplasty. Eur Heart $\mathcal{F} 1987 ; 8$ : 347-53.

7 Norell MS, Lyons JP, Gershlick AH, et al. Assessment of left ventricular performance during coronary angioplasty: a study of intravenous digital subtraction ventriculography. Br Heart f 1988;59:419-28.

8 Rude RE, Poole WK, Muller JE, et al. Electrocardiographic and clinical criteria for recognition of acute myocardial infarction based on analysis of 3,697 patients. $A m \mathcal{f}$ Cardiol 1983;52:936-42.

9 Yusuf S, Pearson M, Sterry H, et al. The entry ECG in the early diagnosis and prognostic stratification of patients with acute myocardial infarction. Eur Heart $\mathcal{f} 1984 ; 5$ $690-6$.

10 Ohman EM, Casey C, Bengtson JR, Pryor D, Tormey W, Horgan JH. Early detection of acute myocardial infarction: additional diagnostic information from serum concentrations of myoglobin in patients without ST elevation. Br Heart ₹ 1990;63:335-8.

11 Marin MM, Teichman SL. Use of rapid serial sampling of creatine kinase $\mathrm{MB}$ for very early detection of myocardial infarction in patients with acute chest pain. Am Heart $f$ 1992;123:354-61.

12 Downie AC, Frost PG, Fielden P, Joshi D, Dancy DM. Bedside measurement of creatine kinase to guide thrombolysis on the coronary care unit. Lancet 1993;341: $452-4$.

13 Stevenson $R$, Ranjadayalan $K$, Wilkinson $P$, Roberts $R$ Timmis AD. Short and long term prognosis of acute myocardial infarction since introduction of thrombolysis.

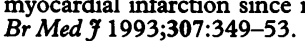

14 LATE Study Group. Late Assessment of Thrombolytic Efficacy (LATE) study with alteplase 6-24 hours after Efficacy (LATE) study with alteplase 6-24 hours after
onset of acute myocardial infarction. Lancet 1993;342: onset of

15 DeWood MA, Spores J, Notske R, et al. Prevalence of total coronary occlusion during the early hours of transmura coronary occlusion during the early hours of transmura

16 DeWood MA, Stiffer WF, Simpson CS, et al. Coronary arteriographic findings soon after non-Q wave myocardial arteriographic findings soon after non-Q wave
infarction. N Engl ₹Med 1986;315:417-23.

17 Timmis AD, Griffin B, Crick JCP, Nelson DJ, Sowton E The effects of early coronary patency on the evolution of myocardial infarction: a prospective arteriographic study. Br Heart $\mathcal{F} 1987 ; 58: 345-51$.

18 Hogg KJ, Hornung RS, Howie CA, Hockings N, Dunn FG, Hillis WS. Electrocardiographic prediction of coronary artery patency after thrombolytic treatment in acute myocardial infarction: use of ST segment as a noninvasive marker. Br Heart $\mathcal{f} 1988 ; 60: 275-80$

19 Saran RK, Been M, Furniss SS, Hawkins T, Reid D Reduction in ST segment elevation after thrombolysi predicts either coronary reperfusion or preservation of left ventricular function. $B r$ Heart $\mathcal{f} 1990 ; 64: 113-7$.

20 Theroux P, Ouimet H, McCans J, et al. Aspirin, heparin or both to treat acute unstable angina. N Engl $\mathcal{Y}$ Med 1988 319:1105-11.

21 Davies MJ, Thomas AC. Plaque fissuring - the cause of acute myocardial infarction, sudden ischaemic cardiac death, and crescendo angina. $B r$ Heart $\mathcal{f} 1985 ; 53$. 363-73.

22 Lee HS, Cross SJ, Garthwaite P. Comparison of the value of novel rapid measurement of myoglobin, creatine kinase, and creatine kinase-MB with the electrocardiogram for the diagnosis of acute myocardial infarction. $B$ Heart $¥ 1994 ; 71: 311-5$. 